\title{
QUAlity of Life Assessment in Spina bifida for Children (QUALAS-C): development and validation of a novel health-related quality of life instrument.
}

Konrad M. Szymanski, MD MPH, ${ }^{a}$ Rosalia Misseri, MD, ${ }^{a}$ Benjamin Whittam, MD MS, ${ }^{\text {a David }}$ Y. Yang, MD, ${ }^{a}$ Sonia-Maria Raposo, LLB, ${ }^{\text {a }}$ Shelly J. King, CPNP, ${ }^{\text {a }}$ Martin Kaefer, MD, ${ }^{a}$ Richard C. Rink, ${ }^{\mathrm{a}} \mathrm{MD}$, Mark P. Cain, MD ${ }^{\mathrm{a}}$

${ }^{a}$ Division of Pediatric Urology, Riley Hospital for Children, Indiana University School of Medicine, Indianapolis, Indiana

\section{Corresponding author:}

Konrad M. Szymanski, MD MPH

Division of Pediatric Urology

Riley Hospital for Children at IU Health

Indiana University School of Medicine

705 Riley Hospital Dr. \#4230

Indianapolis, IN 46205 USA

Office: $317-944-7469$

Fax: 317-944-7481

szymanko@iupui.edu

\section{Abstract word count: 229}

\begin{abstract}
Objective: To develop and validate a self-reported health-related QUAlity of Life $\underline{\text { Assessment }}$

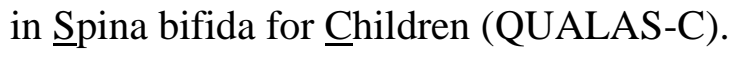

This is the author's manuscript of the article published in final edited form as:

Szymanski, K. M., Misseri, R., Whittam, B., Yang, D. Y., Raposo, S.-M., King, S. J., ... Cain, M. P. (2016). Quality of Life Assessment in Spina Bifida for Children (QUALAS-C): Development and Validation of a Novel Health-related Quality of Life Instrument. Urology, 87, 178-184. http://doi.org/10.1016/j.urology.2015.09.027 
Methods: We drafted a 27-question pilot instrument using a patient-centered comprehensive item generation/refinement process. It was administered to a sample of children 8-12 years old with Spina Bifida $(\mathrm{SB})$ recruited online via social media and in person at an outpatient SB clinic (January 2013-September 2014). Healthy controls were recruited at routine pediatrician visits. Validation and final questions were determined based on clinical relevance, high loadings on factor analysis and domain psychometrics. Children with SB also completed the validated generic Kidscreen-27 instrument.

Results: Median age of 150 participants was 9.6 years (60.7\% male, $72.7 \%$ Caucasian), similar to 46 controls $(p \geq 0.10$ ). There were 97 online and 53 clinic participants $(89.0 \%$ and $84.2 \%$ of eligible, respectively). Face and content validity of the 2-domain, 10-question QUALAS-C were established by patients, parents and experts. Internal consistency and test-retest reliability was high for the Esteem \& Independence and Bladder \& Bowel domains (Cronbach's alpha: 0.720.76, ICC: 0.74-0.77). Correlations between QUALAS-C domains were low $(\mathrm{r}=0.51)$, indicating that QUALAS-C can differentiate between two distinct health-related quality of life (HRQOL) components. Correlations between QUALAS-C and Kidscreen-27 were also low $(\mathrm{r} \leq 0.44)$. QUALAS-C scores were significantly lower in children with SB than without $(\mathrm{p}<0.0001)$.

Conclusions: QUALAS-C is a short, valid HRQOL tool for children with SB. It will be useful in clinical and research settings. 
Manuscript word count: 2487

Keywords: quality of life, spinal dysraphism, meningomyelocele, child, urinary incontinence, fecal incontinence

\section{Acknowledgments}

We would like to thank the many children with Spina Bifida and their parents and caregivers for participating in this study. We also want to thank the following individuals and groups for their help:

Concept and Content Consultant: Kathleen J. Sawin, PhD CPNP-PC FAAN (College of Nursing, University of Wisconsin-Milwaukee/Children's Hospital of Wisconsin).

Content Consultants: Pediatric Urology: John Paul Capolicchio, MD (Montreal Children's Hospital, McGill University), Mohamed Elsherbini, MD (Montreal Children's Hospital, McGill University), Walid Farhat, MD (Hospital for Sick Children, University of Toronto), Richard Grady, MD (Seattle Children's Hospital, University of Washington), Roman Jednak, MD (Montreal Children's Hospital, McGill University), David B. Joseph, MD (University of Alabama at Birmingham), Martin A. Koyle, MD (Hospital for Sick Children, University of Toronto), Andrew L. MacNeilly, MD (British Columbia Children's Hospital, University of British Columbia), JL Pippi Salle, MD (Hospital for Sick Children, University of Toronto), Melissa A. Young, CPNP (Riley Hospital for Children, Indiana University Health). Pediatrics: Timothy J. Brei, MD (Seattle Children's Hospital, University of Washington), Joseph O’Neil, 
MD (Riley Hospital for Children, Indiana University Health). Clinical Pediatric Psychology:

Khush Amaria, PhD (Hospital for Sick Children, University of Toronto).

(Note: The expert panel during Phase 1 of the study comprised of 14 Content Consultants listen above and 7 authors. The local expert panel during Phases 2, 4 and 5 comprised of 7 authors.)

Health Literacy Consultant: Cynthia Latty, RN (Riley Hospital for Children, Indiana University Health).

Statistics Consultants: Robert Haley, MD (University of Texas Southwestern), Patrick Monahan, PhD (Richard M. Fairbanks School of Public Health, Indiana University).

Participant Recruitment: Robin Bowman, MD (Lurie Children's Hospital of Chicago, Northwestern University), Timothy J. Brei, MD (Seattle Children’s Hospital, Seattle Children's Hospital), Jerry Clayton, MD (Children's Hospital Colorado, University of Colorado), Dominic C. Frimberger, MD (The Children's Hospital of Oklahoma, University of Oklahoma), Betsy Hopson, MSHA (Children's Hospital of Alabama, University of Alabama at Birmingham), Alison C. Keenan, MD (Riley Hospital for Children, Indiana University Health), Jill Mazurek, MD (Indiana University Health), Brandon G. Rocque, MD (Children's Hospital of Alabama, University of Alabama at Birmingham), Dorota A. Szczepaniak, MD (Riley Hospital for Children, Indiana University Health). 


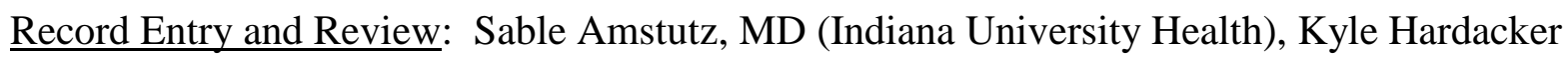
(Indiana University Health), Zoe King (Indiana University Health), Sophie Mazurek (Indiana University Health), Meredith Metcalf, MD (University of Tennessee Health Sciences Centre).

Organizations assisting in participant recruitment: International: International Federation for Spina Bifida and Hydrocephalus. United States: Spina Bifida Association, Spina Bifida Associations of Alabama, the Carolinas, Community of Memphis, Connecticut, Georgia, Greater New England, Illinois, Indiana, Kentucky, Nassau County, New Orleans, North Texas, Texas, Washington, Western Pennsylvania, Wisconsin, SB Resource Network, Spina Bifida Connection, National Birth Defects Prevention Network, Disabled Children of Vietnam Veterans. Canada: Spina Bifida \& Hydrocephalus Association of Canada, Spina Bifida \& Hydrocephalus Association of Ontario, Association de Spina-Bifida et d'Hydrocéphalie du Québec. Europe: Spina Bifida Hydrocephalus Ireland (Ireland), Mid-West Spina Bifida and Hydrocephalus Association (Ireland), Cork Spina Bifida and Hydrocephalus Association (Ireland), Spina bifida Hydrocephalus Information Networking Equality (SHINE, United Kingdom), Arbeitsgemeinschaft Spina Bifida und Hydrocephalus e. V. (ASBH, Germany), Swedish National Association for Disabled Children and Young People (FUB) (Sweden), Asociación Bizkaia Elkartea Espina Bífida e Hidrocefalia (Spain), Fundacja Spina (Poland), Spina Bifida ir Hidrocefalija asociacija (SBHA) (Lithuania). Australia and Oceania: Spina Bifida Foundation Victoria (Australia), Spina Bifida Hydrocephalus Queensland (Australia), Spina Bifida Awareness (New Zealand). Middle East: Lebanese Association for Neuromuscular Diseases for Hope (Lebanon). South America: Associação de Espinha Bífida e Hidrocefalia 
(AEBH, Brazil). Africa: Festus Fajemilo Foundation (Nigeria), National Council for Persons with Physical Disabilities in South Africa (South Africa).

\section{Financial conflicts of interests}

None

\section{Research support}

Funding was provided by the Indiana University School of Medicine's Department of Urology.

Abbreviations: HRQOL: health-related quality of life, SB: Spina Bifida, QUALAS-C: QUAlity of Life Assessment in Spina bifida for Children, SD: standard deviation

\section{Introduction}

Spina bifida (SB) is the most common congenital anomaly of the central nervous system, affecting 3.4 per 10,000 live births in the United States. ${ }^{1}$ Children surviving infancy face neurological, neurosurgical, orthopedic and urological challenges. Unfortunately, studies on health-related quality of life (HRQOL) in children with SB tend to be small, single-institutional studies using limited, poorly-validated, or non-validated, instruments. ${ }^{2-6}$ Others report patient satisfaction, rather than HRQOL. ${ }^{7,8}$ Importantly, generic HRQOL instruments developed for healthy children ${ }^{9,10}$ may be unable to capture small, but clinically important, differences because they were not designed to measure the impact of SB on HRQOL. ${ }^{11}$ Moreover, no validated and comprehensive SB-specific HRQOL instrument exists which incorporates bladder and bowel domains. 
SB-specific HRQOL is a component of quality of life that focuses on an individual's perception of the impact of SB on their physical and psychosocial functioning. ${ }^{11,12}$ Assessing self-reported HRQOL is particularly important, as those with SB often report better HRQOL than perceived by their parents and caregivers. ${ }^{13,14}$ For this reason, instrument development requires input from individuals with $\mathrm{SB}$, their parents and caregivers. ${ }^{2,11}$ An ideal, clinically relevant HRQOL instrument focuses on HRQOL, rather than physical function. It should also possess excellent psychometric properties and be condition-specific, yet remain short and straightforward. ${ }^{2,11}$ Developing such an instrument is challenging in children, since a pediatric instrument must account for children's changing cognitive capacity, reading skills and emotional development. $^{2}$ Our goal was to develop and validate a clinically useful, self-reported, disease-

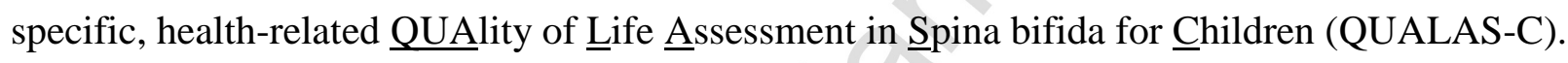

\section{Methods}

The study protocol followed the Federal Drug Administration recommendations for patient-reported outcome instrument development ${ }^{15}$ and was approved by the Internal Review Board (IRB 9470) and the Spina Bifida Association Professional Advisory Council.

\section{$\underline{\text { Eligibility and exclusion criteria }}$}

Children (8 to 12 years old) with a history of myelomeniongocele or lipomeningocele requiring newborn spine surgery and living in the United States were recruited online via social media, or in person at an outpatient multidisciplinary SB clinic. While age cutoffs are somewhat arbitrary, they were necessary to generate QUALAS-C and are supported by clinical experience. Similar ranges were successfully used for other pediatric instruments. ${ }^{9,10}$ 
The questionnaire was administered between January 2013 and September 2014. Noneligibility criteria included: diagnosis other than spina bifida (e.g. primary tethered cord, sacral agenesis), poor self-reported English proficiency ("a little bit," "some," rather than "well," "very well" on a 4-point Likert scale), developmental delay interfering with comprehension of questions, or surgery in the last month. In clinic, developmental delay was assessed by parents, health care providers and investigators, without routine psychological testing. Children participating online were assessed for significant delay by their parents. Eligible participants were excluded if they did not complete the questionnaire. Eligibility and exclusion criteria remained unchanged throughout the study. Healthy controls without SB were recruited from two local pediatric clinics during routine checkup visits.

\section{$\underline{\text { Phase 1. Item generation }}$}

We used a patient-centered, comprehensive item generation and refinement process

(Figure 1). Items were generated from transcripts of 10 semi-structured interviews with children with SB and their families (by KMS). Items were also drafted based on a review of published instruments and the opinions of 21 national and international experts in SB care (see Acknowledgments). The item generation process continued until reaching the saturation point, when no new items were generated. This comprehensive list of 130 items covered 11 child/parent/expert-derived themes of cognition, independence, emotional impact, social interactions, educational, leisure activities, mobility, healthcare interactions, toileting, as well as urinary and fecal continence. This list was reduced to 72 items by an expert panel, who eliminated redundant items, while maintaining the themes. 


\section{Phase 2. Development of pilot instrument}

The 72 items were rated on importance by 6 children with SB and 6 parents from our SB clinic. Ratings were made on a 3-point Likert scale ("not important," "somewhat important," "very important"). After review by a local SB expert panel (see Acknowledgements), 27 items with the highest rankings were selected to create a more manageable and representative pilot QUALAS-C. This item reduction approach has been successfully used in the SB population. ${ }^{4,5,16}$ Some items were reworded to ensure comprehension and clarity. Rewording was based on feedback from the 12 individuals rating the questions and a Health Literacy Educator (see Acknowledgments). Readability was assessed by the Flesch Kincaid Grade Level test. ${ }^{17}$

The pilot QUALAS-C was self-administered. Questions were close-ended and numbered to avoid omission. Similar to other pediatric instruments, questions reflected the 4 weeks prior to answering the questions. ${ }^{5,10,18}$ Responses used a 5-point Likert scale (never, almost never, sometimes, almost always, always), an approach successfully used in other instruments. ${ }^{4,5,9,10,18}$ Items focusing on similar themes were grouped together to simulate the final QUALAS-C instrument.

Phase 3. Further participant recruitment

The pilot QUALAS-C and demographic questionnaire were administered anonymously to 150 children with SB and 46 controls in a cross-sectional survey (January 2013 to September 2014). Children with SB also completed the Kidscreen-27, a validated general HRQOL instrument. ${ }^{9}$ In order to open the study to children from a variety of social and health care setting, participants were recruited through local, national and international SB organizations via social media (see Acknowledgments) and at our outpatient multidisciplinary SB clinic. Consent 
was obtained online (computer-based) or in person (clinic-based). Test-retest reliability was assessed by readministering the QUALAS-C two weeks later to participants recruited in clinic. A \$5 incentive payment was provided.

Phase 4. Refinement of instrument and factor analysis

After reviewing responses to the 27-item pilot QUALAS-C by a panel of local SB experts, one item was removed secondary to a high missing rate ( $>50 \%$ participants did not answer). For adequate statistical power, a factor analysis on the remaining 26 items would require at least 130 participants with $\mathrm{SB}\left(26 \times 5\right.$ participants/item). ${ }^{19,20}$

We used factor analysis to statistically verify which of the child/parent/expert-derived items and themes work well in validated QUALAS-C domains. Briefly, extracted factors were based on 4 criteria: ${ }^{21}$ (1) examining standard scree plots of unrotated and varimax (orthogonal) rotated factor analyses,(2) extracting factor models with different numbers of factors and rotating them using 5 additional rotations (4 orthogonal, 1 oblique) to verify factor structure stability, (3) ensuring extracted factors had at least 3 variables with loadings 0.4 or greater, and (4) confirming statistical properties and clinical plausibility/relevance of each resulting domain. Based on these criteria, the final QUALAS-C instrument consisted of 2 domains with 5 items each. QUALAS-C is scored 0-100, where higher values signify higher HRQOL, and takes <5 minutes to complete.

\section{Phase 5. Validation}

We assessed several types of validity among participants with SB to determine if the 10question QUALAS-C measures what it was intended to measure. ${ }^{22}$ Face and content validity 
were established through a review by patients, families and experts. Construct validity was additionally assessed through factor analysis. For each domain score, we calculated the mean, standard deviation (SD), median, range and the percentage of subjects scoring the minimum (floor) and maximum (ceiling). Reliability, or reproducibility, was assessed by measuring internal consistency and test-retest reliability. ${ }^{22}$ Internal consistency refers to the degree of correlation between items in the instrument. It was measured by Cronbach's alpha (0.7-0.9 signifying robust consistency without redundancy). ${ }^{22}$ Two-week test-retest reliability was assessed by Intraclass Correlation Coefficient (ICC), which accounts for the direction of change ( $\geq 0.7$ indicating good reliability), using a SAS macro written by Lu and Shara. ${ }^{23}$

Convergent and divergent validity evaluates conceptual independence or redundancy. Convergent validity evaluates the degree to which QUALAS-C scores converge with other instruments measuring similar outcomes. On the other hand, divergent validity evaluates the degree to which QUALAS-C scores diverge from those measured by dissimilar instruments. To assess this, we calculated Pearson correlation coefficients (r) among QUALAS-C domains and with Kidscreen-27 domains. To quantify effect size, we used a previously established method of dividing the mean difference between children with SB and controls by the SD of the control population. $^{24,25}$

Several distribution-based approaches were used to determine the minimal clinically important difference that could be detected. Estimated point differences were determined using (1) $0.5 \mathrm{SD},{ }^{26}$ or (2) internal consistency or (3) test-retest reliability in the formula $S D \quad \sqrt{(1 \text { reliability })} \cdot{ }^{27}$ We selected the most conservative, largest point difference calculated by the three methods as the minimally important score difference for each domain.

To further evaluate construct validity, domain scores between children with SB and 
controls were compared using a t-test. A critical $\mathrm{p}=0.05$ was used. All statistical analyses were performed using SAS software (v9.4, SAS Institute, Cary, NC).

\section{Results}

Phases 1 and 2. Item generation and Development of pilot instrument

The 27-item pilot instrument was developed in a multifaceted, patient-centered fashion (Figure 1). Ten semi-structured interviews lasted a mean of 20 minutes.

$\underline{\text { Phase 3. Further participant recruitment (Demographics) }}$

Of 104 clinic patients screened, 63 (60.6\%) met eligibility criteria, and $53(84.1 \%)$ were ultimately enrolled (Figure 2). Of 110 online participants, 109 (99.1\%) met eligibility criteria, and $97(89.0 \%)$ were enrolled. We observed no significant differences in gender and age between eligible children who were and were not enrolled. Forty-six controls without SB were enrolled.

Median age of 150 participants was 9.6 years (60.7\% male, $72.7 \%$ Caucasian), similar to controls ( $\mathrm{p} \geq 0.10$ ) (Table 1). Half (57.3\%) were community ambulators (walked with/without aids, using wheelchair for only long trips ${ }^{28}$ and $63.3 \%$ had a ventriculoperitoneal shunt. Most performed clean intermittent catheterizations (76.7\%) and 59.3\% reported daytime urinary dry intervals of at least $4 \mathrm{~h}$. Participants lived in 34 states of the United States, encompassing $87 \%$ of the country's population in 2011 (eTable 1).

Phase 4. Refinement of instrument and factor analysis 
After removal of one item due to a high missing rate, 26 items were analyzed with factor analysis. A break in the slope of scree plots from two principal factor analyses, unrotated and varimax rotated, suggested the presence of two meaningful factors, followed by a decreasing slope of minor factors (eTable 2). Similar findings were obtained on the other 5 rotations. The first two extracted factors were retained to become QUALAS-C domains (Esteem and Independence, Bladder and Bowel) and accounted for $68.2 \%$ of the total variance.

\section{Phase 5. Validation}

A review by patients, families and experts established face and content validity of the final 10-question QUALAS-C. The Flesch Kincaid Grade Level test indicated a third grade reading level. Characteristics of the QUALAS-C domain scores were calculated among children with SB, without evidence of floor or ceiling effects (Table 2). Each domain had acceptable internal consistency (Cronbach's alpha: 0.72-0.76) and test-retest validity (ICC: 0.74-0.77). The mean two-week test-retest changes were small for each domain (range: -1.0 to +1.1 ). Missing data was acceptably low for each domain (Esteem and Independence: 0.0\%, Bladder and Bowel: 4.7\%).

Correlations between QUALAS-C domains were low ( $\mathrm{r}=0.51)$, indicating that QUALASC can differentiate between two distinct HRQOL components (eTable 3). Correlations between QUALAS-C and Kidscreen-27 domains were also low ( $\mathrm{r} \leq 0.44)$, indicating that these instruments assess different aspects of HRQOL. Domain characteristics were similar for participants recruited online and in clinic.

The minimally important difference was $\geq 10$ for either domain (range of values: 9.710.7). 
QUALAS-C scores for controls were significantly higher than children with SB for both domains ( $p<0.0001)$, each with a large effect size $(\geq 1.1)$ (eTable 4). Similar to children with $\mathrm{SB}$, missing data was low for each domain (Esteem and Independence: 0.0\%, Bladder and Bowel: $0.0 \%)$.

\section{Comment}

We present a short, novel, validated HRQOL instrument developed specifically for children with SB. QUALAS-C is composed of items relevant to children with SB, their families and clinicians, including a comprehensive domain focusing on bladder and bowel dysfunction. We also report minimally important differences in HRQOL scores, which may help patients, clinicians and researchers to focus on differences that are statistically and clinically significant.

Three previously published SB-specific HRQOL instruments in children have serious limitations. Importantly, none have a patient-reported version for children younger than 13 years old. $^{4-6}$ Furthermore, each instrument has 44 to 51 items, making them cumbersome and timeconsuming. Since none of these instruments was designed using factor analysis, all remain suspect for item redundancy and appropriate domain groupings. In addition, the Hydrocephalus

Outcome Questionnaire was developed without input from individuals with $\mathrm{SB}{ }^{5}$ While children, families and SB experts overwhelmingly endorsed bladder/bowel care and incontinence as important aspects of HRQOL, only the Fecal Incontinence and Constipation QOL instrument contains items addressing bowel issues. ${ }^{6}$ Finally, it remains unclear what score difference, or change, may be clinically relevant when using existing instruments.

Our primary goal was to create a clinically meaningful and useful instrument, rather than a research tool. The low rate of missing data suggests that QUALAS-C is not difficult to 
complete. If only 4 of 5 responses are provided for a domain, we suggest using the mean of these items for a domain score. ${ }^{29}$ QUALAS-C domains can be used together or on their own. QUALAS-C was developed because current generic HRQOL instruments are insufficient for children with SB. This is largely due to the fact that instruments developed for healthy children fail to capture aspects of HRQOL important to people living with SB. As the fundamental concept of HRQOL may be different between individuals with and without SB, QUALAS-C scores of healthy controls likely hold no clinical relevance and were used only to calculate validation statistics. QUALAS-C scores may be best compared longitudinally to the same person over time, or between children with SB. Finally, QUALAS-C evaluates the specific impact of SB on HRQOL, rather than generic HRQOL or global quality of life.

Our study has several limitations. While we cannot verify how much assistance online participants received from their parents. It should be noted that while QUALAS-C was often filled out with some parental help in clinic (i.e. reading questions), all questions were assessed from the child's perspective. It is unrealistic to insist that children with SB fill out a HRQOL instrument completely on their own, as few would be able to do so.

Although we did not detect evidence of significant selection bias, as eligible participants who were and were not enrolled had similar demographics, study participants may have fewer developmental and functional limitations than the general SB population and non-participants. An external validation is needed.

While we did not use anchor-based methods to calculate minimally important differences, distribution- and anchor-based methods have been shown to give comparable results. ${ }^{30}$ QUALAS-C was validated only for children with SB. Whether it can be used in other 
populations remains to be seen. Finally, being a validation study, we did not assess risk factors for lower HRQOL. This will be the focus of future work.

\section{Conclusion}

QUALAS-C is a short, validated tool for evaluating HRQOL in children with SB. It assesses important clinical domains, making it a useful instrument in both clinical and potential research settings.

\section{References}

1. Boulet SL, Yang Q, Mai C et al.: Trends in the postfortification prevalence of spina bifida and anencephaly in the United States. Birth Defects Res A Clin Mol Teratol 2008; 82: 527-532.

2. Sawin KJ and Bellin MH: Quality of life in individuals with spina bifida: a research update. Dev Disabil Res Rev 2010; 16: 47-59.

3. MacNeily AE, Jafari S, Scott $\mathrm{H}$ et al.: Health related quality of life in patients with spina bifida: a prospective assessment before and after lower urinary tract reconstruction. $\mathbf{J}$ Urol 2009; 182: 1984-1991.

4. Parkin PC, Kirpalani HM, Rosenbaum PL et al.: Development of a health-related quality of life instrument for use in children with spina bifida. Qual Life Res 1997; 6: 123-132.

5. Kulkarni AV, Rabin D and Drake JM: An instrument to measure the health status in children with hydrocephalus: the Hydrocephalus Outcome Questionnaire. J Neurosurg 2004; 101: 134-140.

6. $\quad$ Nanigian DK, Nguyen T, Tanaka ST et al.: Development and validation of the fecal incontinence and constipation quality of life measure in children with spina bifida. J Urol 2008; 180: 1770-1773; discussion 1773.

7. Salter MJ: What are the differences in body image between patients with a conventional stoma compared with those who have had a conventional stoma followed by a continent pouch? J Adv Nurs 1992; 17: 841-848.

8. Ellsworth PI, Webb HW, Crump JM et al.: The Malone antegrade colonic enema enhances the quality of life in children undergoing urological incontinence procedures. J Urol 1996; 155: 1416-1418.

9. Ravens-Sieberer U, Auquier P, Erhart M et al.: The KIDSCREEN-27 quality of life measure for children and adolescents: psychometric results from a cross-cultural survey in 13 European countries. Qual Life Res 2007; 16: 1347-1356.

10. Varni JW, Seid M and Rode CA: The PedsQL: measurement model for the pediatric quality of life inventory. Med Care 1999; 37: 126-139. 
11. Waters E, Davis E, Ronen GM et al.: Quality of life instruments for children and adolescents with neurodisabilities: how to choose the appropriate instrument. Dev Med Child Neurol 2009; 51: 660-669.

12. Bullinger M, Anderson R, Cella D et al.: Developing and evaluating cross-cultural instruments from minimum requirements to optimal models. Qual Life Res 1993; 2: 451459.

13. Parekh AD, Trusler LA, Pietsch JB et al.: Prospective, longitudinal evaluation of health related quality of life in the pediatric spina bifida population undergoing reconstructive urological surgery. J Urol 2006; 176: 1878-1882.

14. Lemelle JL, Guillemin F, Aubert D et al.: Quality of life and continence in patients with spina bifida. Qual Life Res 2006; 15: 1481-1492.

15. Patrick DL, Burke LB, Powers JH et al.: Patient-reported outcomes to support medical product labeling claims: FDA perspective. Value Health 2007; 10 Suppl 2: S125-137.

16. Sawicki GS, Lukens-Bull K, Yin X et al.: Measuring the transition readiness of youth with special healthcare needs: validation of the TRAQ--Transition Readiness Assessment Questionnaire. J Pediatr Psychol 2011; 36: 160-171.

17. Kincaid JP, Fishburne LRP, Jr., Rogers RL et al.: Derivation of new readability formulas (Automated Readability Index, Fog Count and Flesch Reading Ease Formula) for Navy enlisted personnel. Research Branch Report 8-75 1975: 1-48.

18. Topolski TD, Patrick DL, Edwards TC et al.: Quality of life and health-risk behaviors among adolescents. J Adolesc Health 2001; 29: 426-435.

19. Bryant FB and Yarnold PR: Principal components analysis and exploratory and confirmatory factor analysis, in Grimm LG and Yarnold RR: Reading and understanding multivariale statistics. Washington, DC, American Psychological Association, 1995, pp 99-136.

20. Gorsuch RL: Factor analysis. Hillsdale, N.J., L. Erlbaum Associates, 1983, pp xvii, 425 p.

21. Streiner DL: Figuring out factors: the use and misuse of factor analysis. Can J Psychiatry 1994; 39: 135-140.

22. Streiner DL and Norman GR: Health measurement scales : a practical guide to their development and use. Oxford ; New York, Oxford University Press, 2003, pp xii, 283 p.

23. Lu LNS: Reliability analysis: calculate and compare intra-class correlation coefficients (ICC) in SAS.: Proceedings of NESUG (NorthEast SAS Users Group). 2007.

24. Cohen J: A power primer. Psychol Bull 1992; 112: 155-159.

25. Hays RD, Farivar SS and Liu H: Approaches and recommendations for estimating minimally important differences for health-related quality of life measures. COPD 2005; 2: 63-67.

26. Norman GR, Sloan JA and Wyrwich KW: The truly remarkable universality of half a standard deviation: confirmation through another look. Expert Rev Pharmacoecon Outcomes Res 2004; 4: 581-585.

27. Wyrwich KW, Bullinger M, Aaronson $\mathrm{N}$ et al.: Estimating clinically significant differences in quality of life outcomes. Qual Life Res 2005; 14: 285-295.

28. Hoffer MM, Feiwell E, Perry R et al.: Functional ambulation in patients with myelomeningocele. J Bone Joint Surg Am 1973; 55: 137-148.

29. Skevington SM, Lotfy M, O'Connell KA et al.: The World Health Organization's WHOQOL-BREF quality of life assessment: psychometric properties and results of the 
international field trial. A report from the WHOQOL group. Qual Life Res 2004; 13 : 299-310.

30. Wyrwich KW and Wolinsky FD: Identifying meaningful intra-individual change standards for health-related quality of life measures. J Eval Clin Pract 2000; 6: 39-49.

\section{Figure legends}

Figure 1. Creation of the QUAlity of Life Assessment in Spina bifida in Children (QUALAS-C)

Abbreviations: SB: Spina Bifida.

Figure 2. Enrollment of children into the study

Children were enrolled at an outpatient multidisciplinary spina bifida as well as online via social media. Enrollment commenced in January 2013 through September 2014 (20 months). Healthy controls without SB were recruited from two local pediatric clinics during routine checkup visits.

Table 1. Population characteristics.

\begin{tabular}{|l|c|c|c|}
\hline Patient Characteristics & $\begin{array}{c}\text { Participants } \\
(\mathrm{n}=150)\end{array}$ & Controls $(\mathrm{n}=46)$ & -value \\
\hline Age, mean (SD), years & $9.6(1.4)$ & $10.0(1.2)$ & 0.10 \\
\hline Male gender, No. (\%) & $91(60.7 \%)$ & $25(54.3 \%)$ & 0.49 \\
\hline Race & & & \\
\hline Caucasian & $109(72.7 \%)$ & $28(60.8 \%)$ & 0.14 \\
\hline Hispanic & $21(14.0 \%)$ & $3(6.5 \%)$ & \\
\hline African-American & $6(4.0 \%)$ & $7(15.2 \%)$ & \\
\hline East Asian & $7(4.7 \%)$ & $0(0.0 \%)$ & \\
\hline Native & $1(0.7 \%)$ & $0(0.0 \%)$ & \\
\hline Multiethnic & $5(3.3 \%)$ & $8(17.4 \%)$ & \\
\hline Unknown & $1(0.7 \%)$ & $0(0.0 \%)$ & \\
\hline Household arrangements, No. (\%) & & & \\
\hline Parent(s) & $145(96.7 \%)$ & $44(95.7 \%)$ & 0.67 \\
\hline Other & & & \\
\hline
\end{tabular}




\begin{tabular}{|c|c|c|c|}
\hline Grandparent(s) only & $4(2.7 \%)$ & $0(0.0 \%)$ & \\
\hline Uncle/aunt only & $0(0.0 \%)$ & $2(4.4 \%)$ & \\
\hline Unknown & $1(0.7 \%)$ & $0(0.0 \%)$ & \\
\hline \multicolumn{4}{|l|}{ Mobility, No. (\%) } \\
\hline Community ambulator & $86(57.3 \%)$ & $46(100.0 \%)$ & $<0.001$ \\
\hline Not a community ambulator & $59(39.3 \%)$ & $0(0.0 \%)$ & \\
\hline Unknown & $5(3.3 \%)$ & $0(0.0 \%)$ & \\
\hline \multicolumn{4}{|l|}{$\begin{array}{l}\text { Ventriculoperitoneal shunt, No. } \\
(\%)\end{array}$} \\
\hline Yes & $95(63.3 \%)$ & $0(0.0 \%)$ & \\
\hline No & $45(30.0 \%)$ & $46(100.0 \%)$ & $<0.001$ \\
\hline Unknown & $10(6.7 \%)$ & $0(0.0 \%)$ & \\
\hline \multicolumn{4}{|l|}{$\begin{array}{l}\text { Clean intermittent } \\
\text { catheterizations, No. (\%) }\end{array}$} \\
\hline Yes & $115(76.7 \%)$ & $0(0.0 \%)$ & $<0.001$ \\
\hline No & $32(21.3 \%)$ & $46(100.0 \%)$ & \\
\hline Unknown & $3(2.0 \%)$ & $0(0.0 \%)$ & \\
\hline \multicolumn{4}{|l|}{$\begin{array}{l}\text { Social urinary continence ( } \geq 4 \mathrm{~h} \text { dry } \\
\text { period), No. }(\%)\end{array}$} \\
\hline Yes & $89(59.3 \%)$ & $45(97.8 \%)$ & $<0.001$ \\
\hline No & $59(39.3 \%)$ & $1(2.2 \%)$ & \\
\hline Unknown & $2(1.3 \%)$ & $0(0.0 \%)$ & \\
\hline Catheterizable channel, No. (\%) & 20 & & \\
\hline Yes & $52(34.7 \%)$ & $46(100.0 \%)$ & $<0.001$ \\
\hline No & $88(58.7 \%)$ & $0(0.0 \%)$ & \\
\hline Unknown & $10(6.7 \%)$ & $0(0.0 \%)$ & \\
\hline \multicolumn{4}{|c|}{ Bladder augmentation, No. (\%) } \\
\hline Yes & $39(26.0 \%)$ & $46(100.0 \%)$ & $<0.001$ \\
\hline No & $98(65.3 \%)$ & $0(0.0 \%)$ & \\
\hline Unknown & $13(8.7 \%)$ & $0(0.0 \%)$ & \\
\hline
\end{tabular}

Totals may not add up to $100 \%$ due to rounding.

Abbreviations: SD, standard deviation.

${ }^{a}$ Native American, Alaska Native, Inuit, Aboriginal, Maori, etc.

Table 2. Domain characteristics of the self-reported QUALAS-C

\begin{tabular}{|c|c|c|c|c|c|c|c|c|}
\hline Domain & $\mathrm{N}$ & $\begin{array}{c}\% \\
\text { missin } \\
\mathrm{g}\end{array}$ & $\begin{array}{c}\text { Mea } \\
\mathrm{n} \\
(\mathrm{SD})\end{array}$ & $\begin{array}{c}\text { Median } \\
(\text { Range } \\
)\end{array}$ & $\begin{array}{c}\% \\
\text { Scoring } \\
\text { Minimu } \\
\mathrm{m}\end{array}$ & $\begin{array}{c}\% \\
\text { Scoring } \\
\text { Maximu } \\
\mathrm{m}\end{array}$ & $\begin{array}{c}\text { Cronbach' } \\
\text { s alpha }\end{array}$ & $\begin{array}{c}\text { Test- } \\
\text { retest } \\
\text { reliabilit } \\
\mathrm{y}(\text { ICC) }\end{array}$ \\
\hline $\begin{array}{l}\text { Esteem and } \\
\text { Independen }\end{array}$ & $\begin{array}{c}15 \\
0\end{array}$ & 0.0 & $\begin{array}{c}71.6 \\
(19.3\end{array}$ & $\begin{array}{c}72.5 \\
(10.0-\end{array}$ & 0.0 & 12.7 & 0.72 & 0.77 \\
\hline
\end{tabular}




\begin{tabular}{|c|c|c|c|c|c|c|c|c|}
\hline ce & & & ) & $100.0)$ & & & & \\
\hline $\begin{array}{c}\text { Bladder and } \\
\text { Bowel }\end{array}$ & $\begin{array}{c}14 \\
3\end{array}$ & 4.7 & $\begin{array}{c}70.7 \\
(21.0\end{array}$ & $\begin{array}{c}70.0 \\
(15.0-\end{array}$ & 0.0 & 14.0 & 0.76 & 0.74 \\
\hline
\end{tabular}

Abbreviations: QUALAS-C: QUAlity of Life Assessment in Spina bifida for Children; SD:

Standard Deviation; ICC: Intraclass Correlation Coefficient. 


\section{Editorial Comment}

Re: QUAlity of Life Assessment in Spina bifida for Children (QUALAS-C): development and validation of a novel health-related quality of life instrument

John C. Thomas, MD, FAAP, FACS

Associate Professor of Urologic Surgery

Division of Pediatric Urology

Monroe Carell Jr. Children's Hospital at Vanderbilt

Nashville, TN

615-936-1060

Beeper: 615-835-8060

FAX: 615-936-1061

john.thomas@vanderbilt.edu

\section{No financial disclosures}

The goal of caring for a child with spina bifida should be to help them live as normal a life as possible. In order to achieve this goal, we as providers may perform procedures that are medically necessary as well as those that help them to become more independent and "fit" better into everyday life. Who decides what is "normal"? The challenge of managing patients with a birth defect that results in varying degrees of physical limitations, bowel and bladder dysfunction, and neurologic issues becomes even more difficult as the child ages. Along with the potential need of undergoing multiple surgeries, these individuals must work toward independence in the face of aging parents or caregivers, integrate themselves into school and work, strive for a sense of belonging into a society filled with discrimination and prejudice, and ultimately be provided adequate access to medical care as they transition into adulthood. Despite advances in medical care, it is still quite difficult to compare outcomes across institutions as we have yet to standardize our approach to patients with spina bifida. The current paper highlights 
the importance of having a tool to truly measure health related quality of life in this patient population. As stated, quality of life can be perceived very differently between guardian and patient yet, both reported outcomes are extremely important to us as caretakers to ensure that we are on the right path to counsel and prepare both guardian and child for their journey ahead. Despite the mentioned limitations and need for external validation, this construction of a selfreported health related quality of life assessment tool is one more step to helping these children communicate how their lives are affected by spina bifida. In return, we can use this information to help personalize our approach to each individual patient to help them achieve the best possible outcomes. 